ISSN 2306-1561

Automation and Control in Technical Systems (ACTS)

2014, No 1.2(9), pp. 61-69.

DOI: $10.12731 / 2306-1561-2014-1-19$

\title{
Research of stability and quality of Automated Control System for thermoelectric object with using log-frequency method
}

\section{Nikolaev Andrey Borisovich}

Russian Federation, Honoris Causa, Doctor of Technical Sciences, Professor, Dean of the Faculty «Control Systems».

State Technical University - MADI, 125319, Russian Federation, Moscow, Leningradsky prospekt, 64. Tel.: +7 (499) 151-64-12. http://www.madi.ru

\section{nikolaev.madi@mail.ru}

\section{Ni Zaw}

Republic of the Union of Myanmar, Postgraduate Student, Department of «Automated Control Systems».

State Technical University - MADI, 125319, Russian Federation, Moscow, Leningradsky prospekt, 64. Tel.: +7 (499) 151-64-12. http://www.madi.ru

\begin{abstract}
The article describes that, calculation of log-frequency method of automatic control system for thermoelectric object. As a result of computer simulation shows that the estimates of stability and quality of transient response ACS for thermoelectric object by calculating logfrequency method and using different regulation laws.
\end{abstract}

Keywords: thermoelectric object, log-frequency method (bode plot), temperature control system, automatic control system. 
ISSN 2306-1561

Автоматизация и управление в технических системах (АУТС) 2014. - №1.2(9). - C. 61-69.

DOI: $10.12731 / 2306-1561-2014-1-19$

УДК 681.51.01

\section{Исследование устойчивости и качества системы автоматического управления термоэлектрическим объектом с помощью частотного метода}

\section{Николаев Андрей Борисович}

Российская Федерация, Лауреат премии правительства РФ, Заслуженный деятель науки РФ, доктор технических наук, профессор, декан факультета «Управление».

ФГБОУ ВПО «Московский автомобильно-дорожный государственный технический университет (МАДИ)», 125319, Российская Федерация, г. Москва, Ленинградский проспект, д.64, Тел.: +7 (499) 151-64-12, http://www.madi.ru

nikolaev.madi@mail.ru

\section{Ни 3 о}

Республика Союза Мьянма, аспирант кафедры «Автоматизированные системы управления».

ФГБОУ ВПО «Московский автомобильно-дорожный государственный технический университет (МАДИ)», 125319, Российская Федерация, г. Москва, Ленинградский проспект, д.64, Тел.: +7 (499) 151-64-12, http://www.madi.ru

nizaw.miet@gmail.com

Аннотация. В статье рассматривается частотные методы анализа систем автоматического управления термоэлектрическим объектом. Проведено компьютерное моделирование и показано, что оценки запасов устойчивости и показатели качества системы автоматического управления (САУ) с исследуемым объектом по ЛЧХ разомкнутой системы при различных законах регулирования.

Ключевые слова: логарифмические частотные характеристики (ЛЧХ), термоэлектрический объект, теория автоматического управления (ТАУ), система регулирования температуры.

\section{1. Введение}

В настоящее время весьма актуальной является задача повышения надежности работы термоэлектрических объектов, которые получили широкое распространение в 
полупроводниковой технике, радиоэлектронике, электроэнергетике, бытовой технике. Термоэлектрические приборы находят широкое применение, как в быту, так и во многих областях науки и техники. В данной статье проводится исследование системы устойчивости и качества САУ термоэлектрическим объектом [1, 5, 7 - 15].

\section{2. Математическое описание объекта управления}

Качество анализа и синтеза частотных методов САУ состоит в том, что частотные характеристики разрешают легко выявлять воздействие того или иного параметра на объект динамической системы (переходной процесс, устойчивость). Затем, частотные характеристики можно оценить экспериментально [10]. Это важно в тех случаях, когда трудно составить управнения динамики системы (например - для системы с распределенными параметрами). Частотные характеристики термоэлектрического объекта управления формируются на основании их передаточных функций. В данной статье математическое описание термоэлектрического объекта управления (ОУ) в виде передаточной функции получено в результате идентификации по экспериментальной временной характеристике $h(t)$ термоэлектрического объекта $[1-5,7]$ :

$$
W_{0}(p)=K_{0} / T_{0 \cdot p}+1
$$

где $K_{0}=10,3 \mathrm{~K} / \mathrm{B}$ - коэффициент передачи объекта управления, $T_{0}=960 \mathrm{c}-$ постоянная времени объекта. В этом случае, применение частотных методов позволяет оценить, как запасы устойчивости (по амплитуде $L_{h}$ и по фазе $\gamma$ ), так и основные показатели качества (время регулирования tр и перерегулирование $\sigma$ ) [6].

Рассмотрим статическую систему, в которой управление происходит по пропорциональному закону (П-закон). Передаточные функции регулятора или устройства управления $W_{\text {уу }}(p)$, объекта управления $W_{O Б}(p)$, датчика $W_{\text {Дат }}(p)$ и в целом разомкнутой САУ $W_{\text {раз }}(p)$ приведены ниже. На рисунке 1 приведены логарифмические частотные амплитудная $L(\omega)$ и фазовая $\varphi(\omega)$ характеристики системы при постоянных времени объекта $T_{0}=1 / \omega 1=960 \mathrm{c}$ и датчика $T_{\text {Дат }}=1 / \omega^{2}=$ $2 c$ и общем коэффициенте усиления САУ $K_{c}=50$. Как видно из рисунка 1 , частота среза при таких параметрах небольшая $\omega_{c p}=0,05 \mathrm{c}^{-1}$, запасы устойчивости достаточные $\left(\gamma=90^{\circ} ; L h \rightarrow \infty\right)$, что позволяет оценить быстродействие и колебательность системы. $t p \approx 4 \pi / \omega c p=240 c ; \sigma<13 \%$. Как известно, статическая ошибка САУ определяется величиной коэффициента усиления согласно формуле:

$$
\varepsilon_{y c m}=\frac{A}{1+K_{c}} \approx \frac{A}{K_{c}}
$$

Если на вход системы подается типовой сигнал $A \cdot 1(t)$ и его амплитуда $A=1$ (усл. ед), то $\varepsilon_{\text {уст }}=1 / 50=0,02$ (усл. ед) при $K_{c}=50$. Если необходимо статическую ошибку уменьшить, то КП надо увеличить, увеличивается при этом $K_{c}$, вследствие чего $L(\omega)$ перемещается вверх параллельно исходному состоянию, увеличивается величина $\omega_{c p}$. 
Но при этом уменьшается запас устойчивости по фазе, что может привести к росту колебательности и времени переходного процесса.

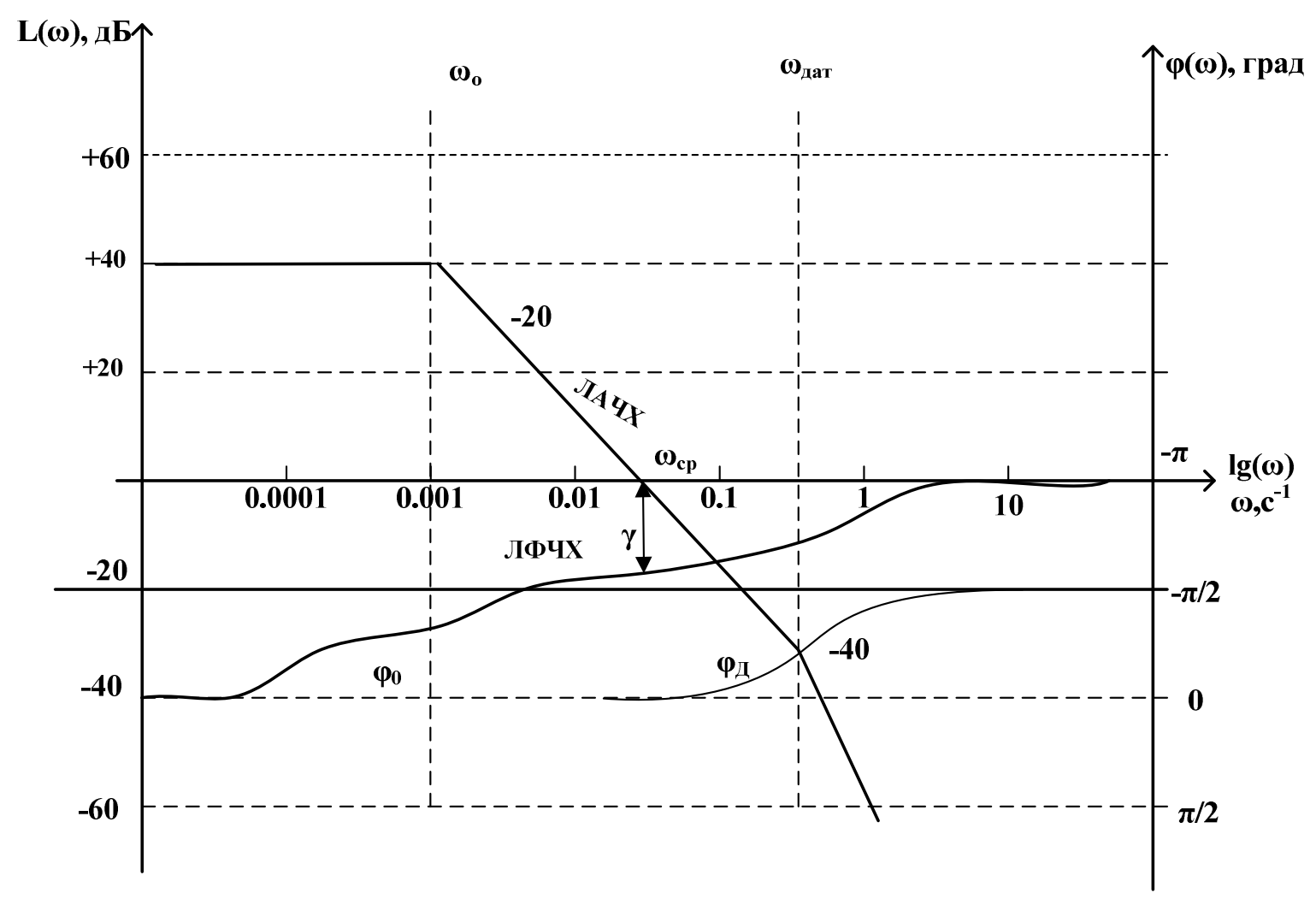

Рисунок 1 - ЛЧХ САУ термоэлектрическим объектом с П-регулятором

Передаточные функции управляющего устройства $W_{\text {уУ }}(p)$, датчика $W_{\partial а т}(p)$ и в целом разомкнутой САУ $W_{\text {раз }}(p)$ имеют вид:

$$
W_{\text {УУ }}(p)=K_{\Pi} ; W_{\text {дат }}(p)=\frac{K_{\text {дат }}}{1+T_{\text {дат }} \cdot p} ; W_{p a з}(p)=\frac{K_{c}}{\left(T_{O} \cdot p+1\right) \cdot\left(T_{\text {дат }} \cdot p+1\right)}
$$

где $K_{c}=K_{\Pi} \cdot K_{O} \cdot K_{\text {Дат }}=50$.

Рассмотрим астатическую систему, в которой управление происходит по ПИзакону. Передаточные функции регулятора или устройства управления $W_{y у}(p)$, объекта управления $W_{O Б}(p)$, датчика $W_{\text {Дат }}(p)$ и в целом разомкнутой САУ $W_{\text {раз }}(p)$ приведены:

$$
W_{\text {pas }}(P)=\frac{K_{O} \cdot K_{\text {Дат }} \cdot\left(T_{y} \cdot p+1\right)}{T_{И} \cdot p \cdot\left(T_{O} \cdot p+1\right) \cdot\left(T_{\text {Дат }} \cdot p+1\right)}
$$

На рисунке 2 приведены ЛАЧХ и ЛФЧХ при тех же значениях постоянных времени $T_{0}$ и $T_{\text {Дат, }}$ что в предыдущих вариантах закона управления. Постоянная времени интегрирования $T_{И}=10 \mathrm{c}$. Общий коэффициент усиления (или передачи) САУ $K_{c}=\frac{\kappa_{0} \cdot K_{\text {Дат }}}{T_{и}}=0,5 \mathrm{c}^{-1}$. Как видно из рисунка 2 , частота среза при таких параметрах:

$$
\omega_{c p}=0,2 c^{-1}
$$




$$
\begin{aligned}
& \omega_{1}=1 / T_{0}=0,001 c^{-1} ; \\
& \omega_{2}=1 / T_{\text {дam }}=0,5 c^{-1} ; \\
& \omega_{3}=1 / T_{y}=0,002 c^{-1} .
\end{aligned}
$$

Запасы устойчивости при этом достаточно большие $\left(\gamma=50^{\circ} ; L h \rightarrow \infty\right)$. Показатели качества переходного процесса: $t_{p} \approx 60 \mathrm{c}, \sigma<13 \%$.

Статическая ошибка САУ будет равна нулю при любом коэффициенте усиления, поэтому величина $K_{c}$ варьируется при необходимости изменения $t_{p}$ и $\sigma$.

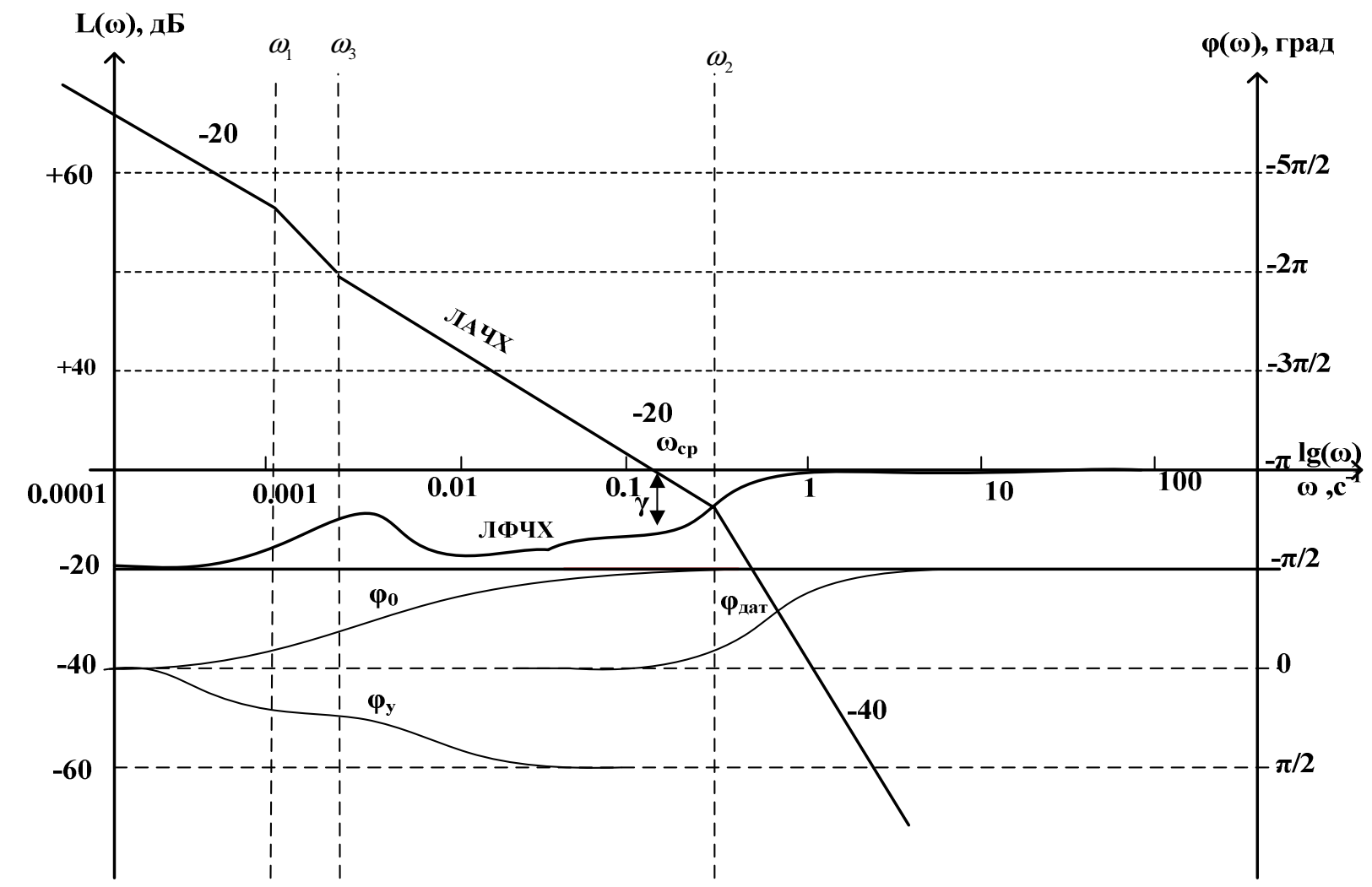

Рисунок 2 - ЛЧХ САУ термоэлектрическим объектом с ПИ-регулятором

\section{3. Компьютерное моделирование САУ термоэлектрическим объектом}

Такое математическое описание дает возможность использовать его в программных пакетах МОДОС и Matlab. Для моделирования переходных процессов показатели качества САУ термоэлектрическим объектом в данной работе будет использован пакет Matlab. Структурная математическая модель статической системы управления термическим оборудованием в объекте управления (ОУ) с П пропорциональным законом регулирования показана на рисунке 3. 


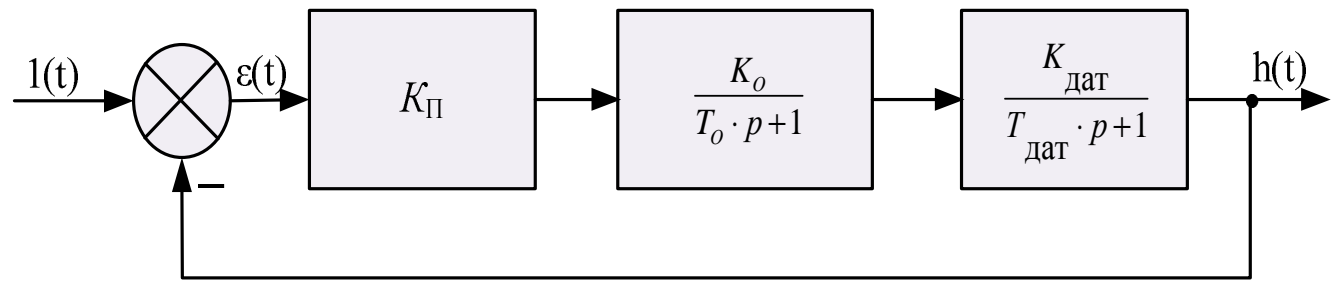

Рисунок 3 - Структурная математическая модель системы управления термическим оборудованием с П - законом регулирования

Схема моделирования с П-регулятором показана на рисунке 4, а переходные процессы для неё приведены на рисунках 5 (а и б). Полученные результаты по определению переходных процессов в САУ приведены в таблице 1.

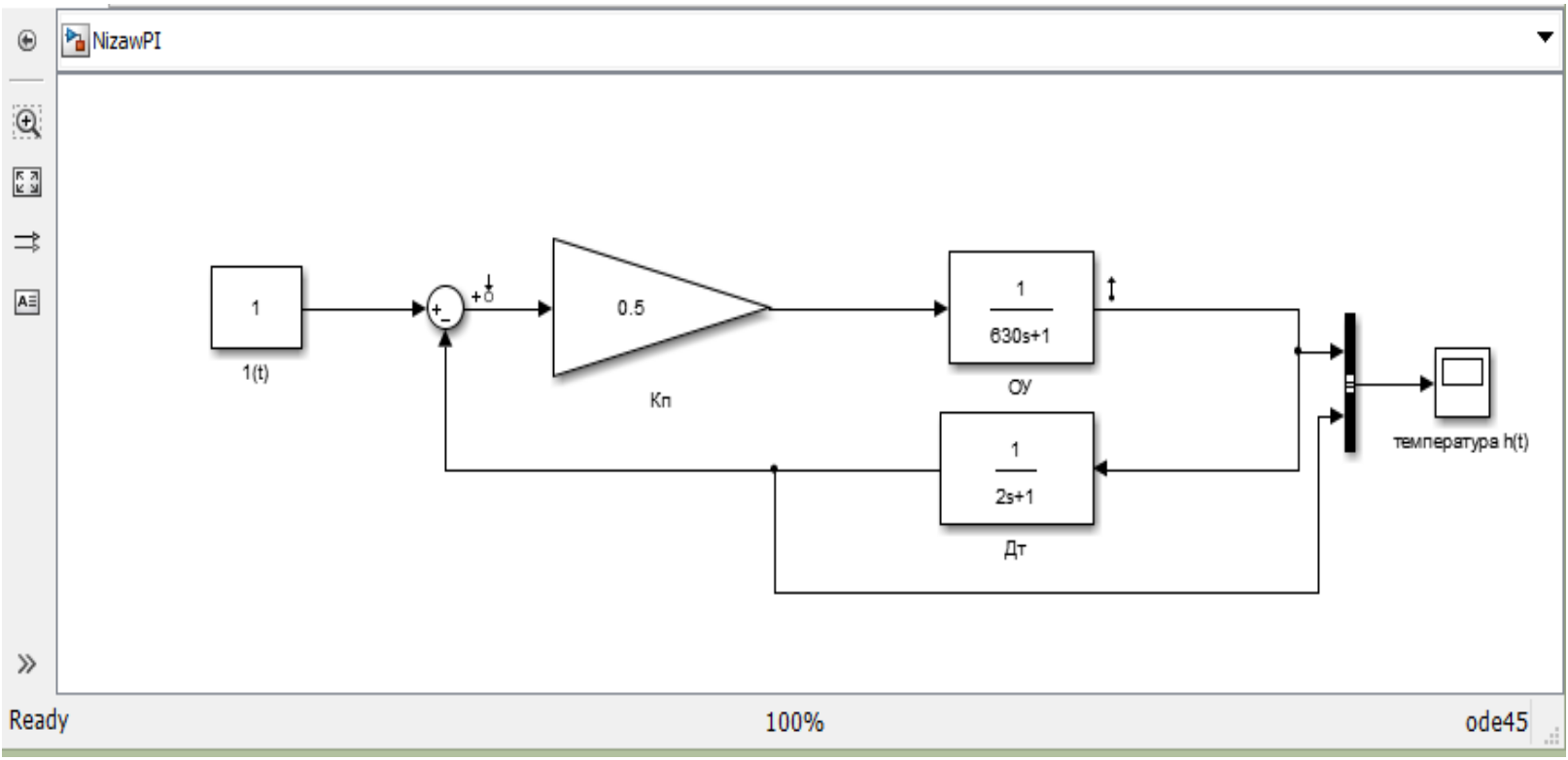

Рисунок 4 - Схема моделирования системы управления термическим оборудованием с П-законом регулирования

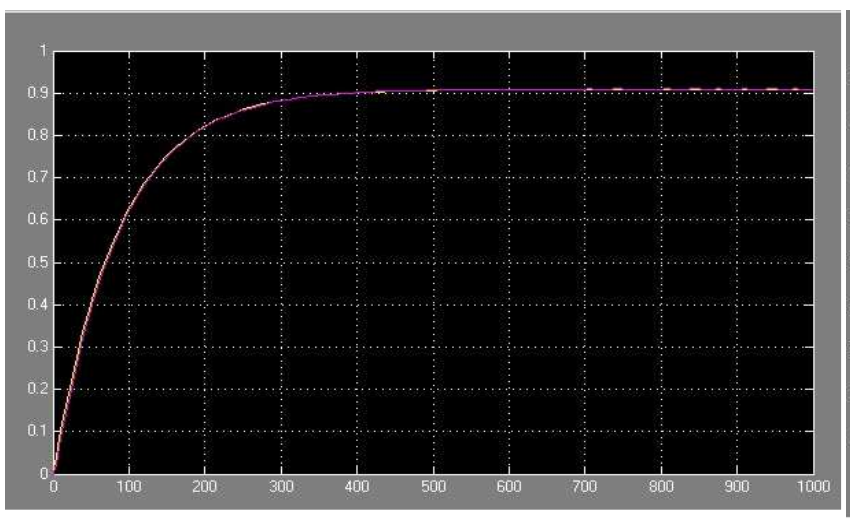

a) $K_{C}=10$

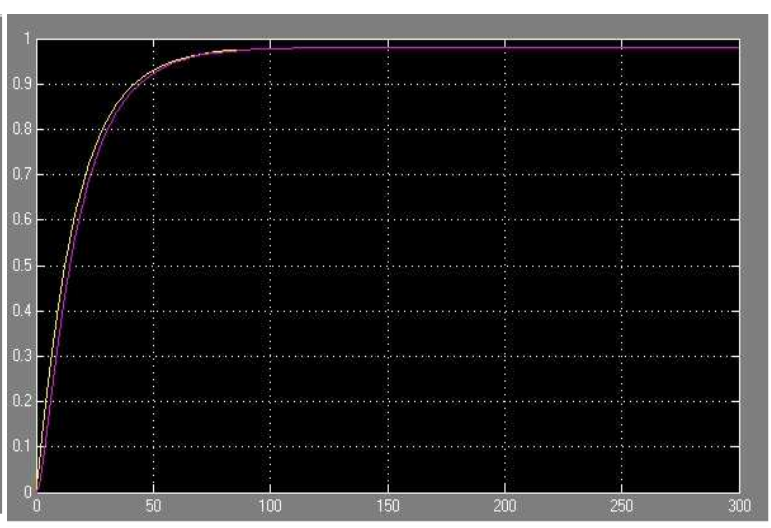

б) $\boldsymbol{K}_{C}=\mathbf{5 0}$

Рисунок 5 - Переходные процессы в системе управления термическим оборудованием с П-законом 
Таблица 1 - Показатели качества П-регулятора

\begin{tabular}{|c|c|c|}
\hline & $\boldsymbol{K}_{\boldsymbol{C}}=\mathbf{1 0}$ & $\boldsymbol{K}_{\boldsymbol{C}}=\mathbf{5 0}$ \\
\hline$t_{p}, \boldsymbol{c}$ & 243 & 65 \\
\hline$\sigma, \%$ & 0 & 0 \\
\hline$\varepsilon_{y c m}$ & 0,1 & 0,98 \\
\hline
\end{tabular}

Далее, рассматривается структурная математическая модель непрерывной системы управления термическим оборудованием с пропорционально - интегральном (ПИ) законом регулирования. Структурная схема разработанной САУ представлена на рисунок 6.

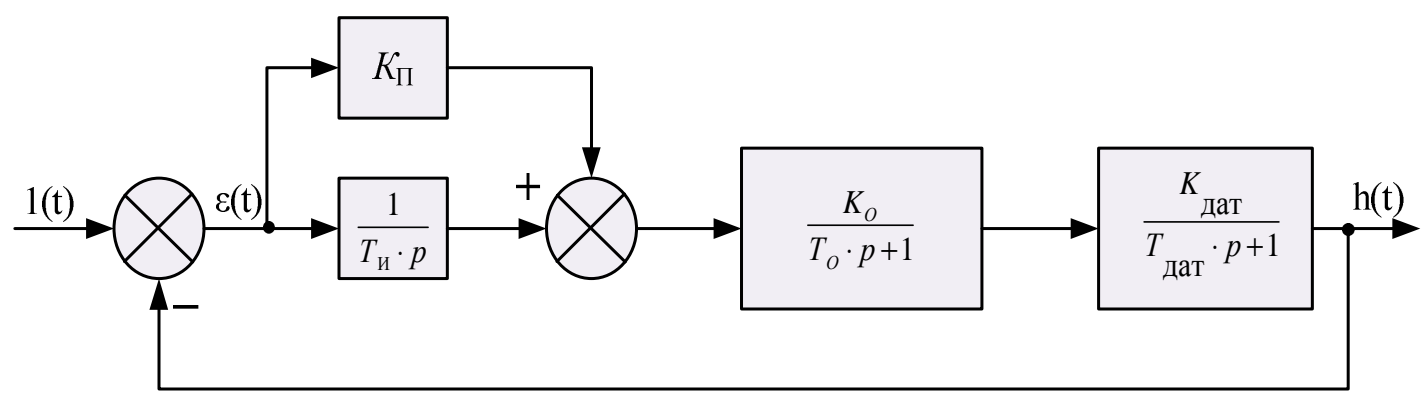

\section{Рисунок 6 - Структурная математическая модель системы управления} термическим оборудованием с ПИ - законом регулирования

Схема моделирования с П-регулятором показана на рисунке 7, а переходные процессы для неё приведены на рисунке 8 (а и б). Полученные результати по определению переходных процессов в САУ приведены в таблице 2.

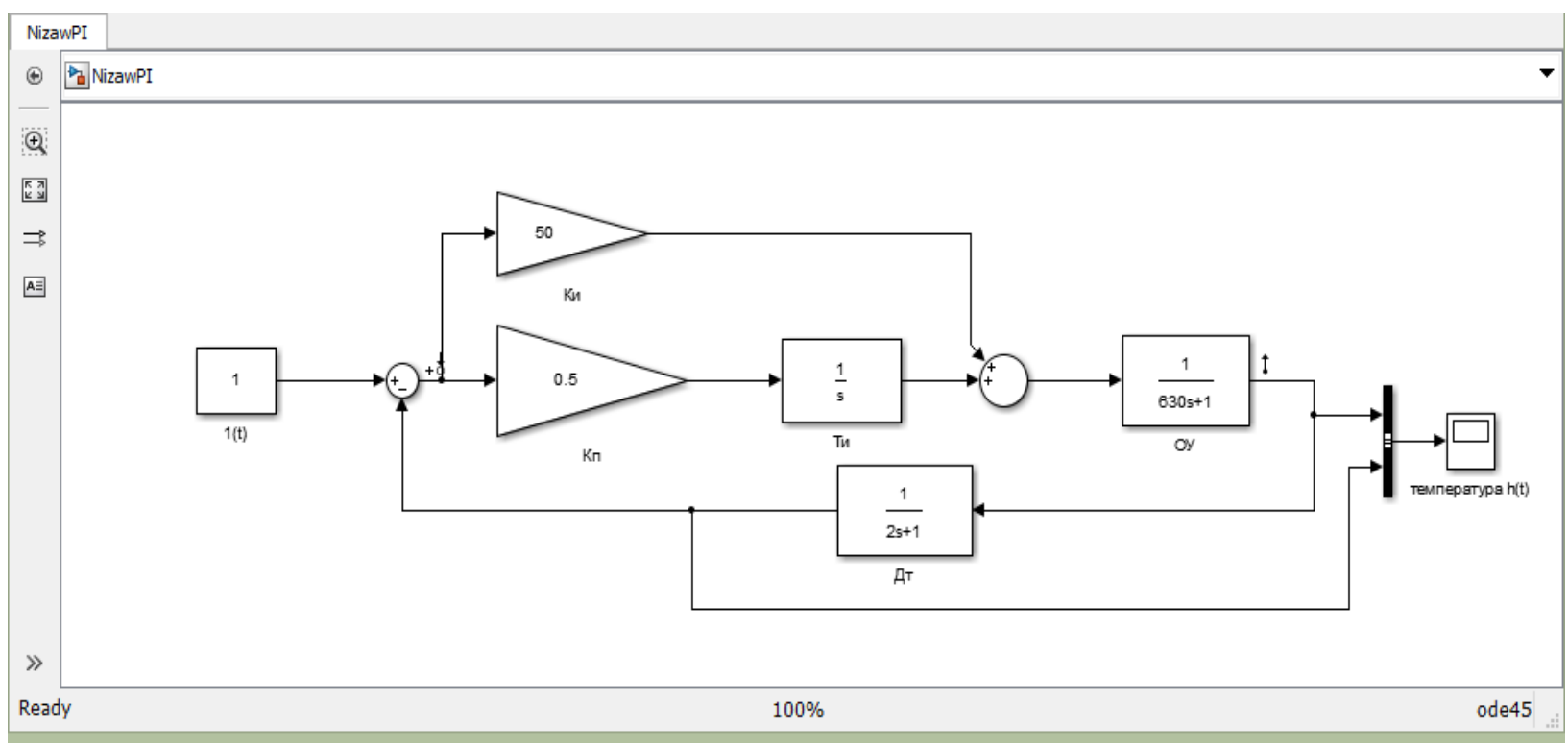

Рисунок 7 - Схема моделирования системы управления термическим оборудованием с П-законом 


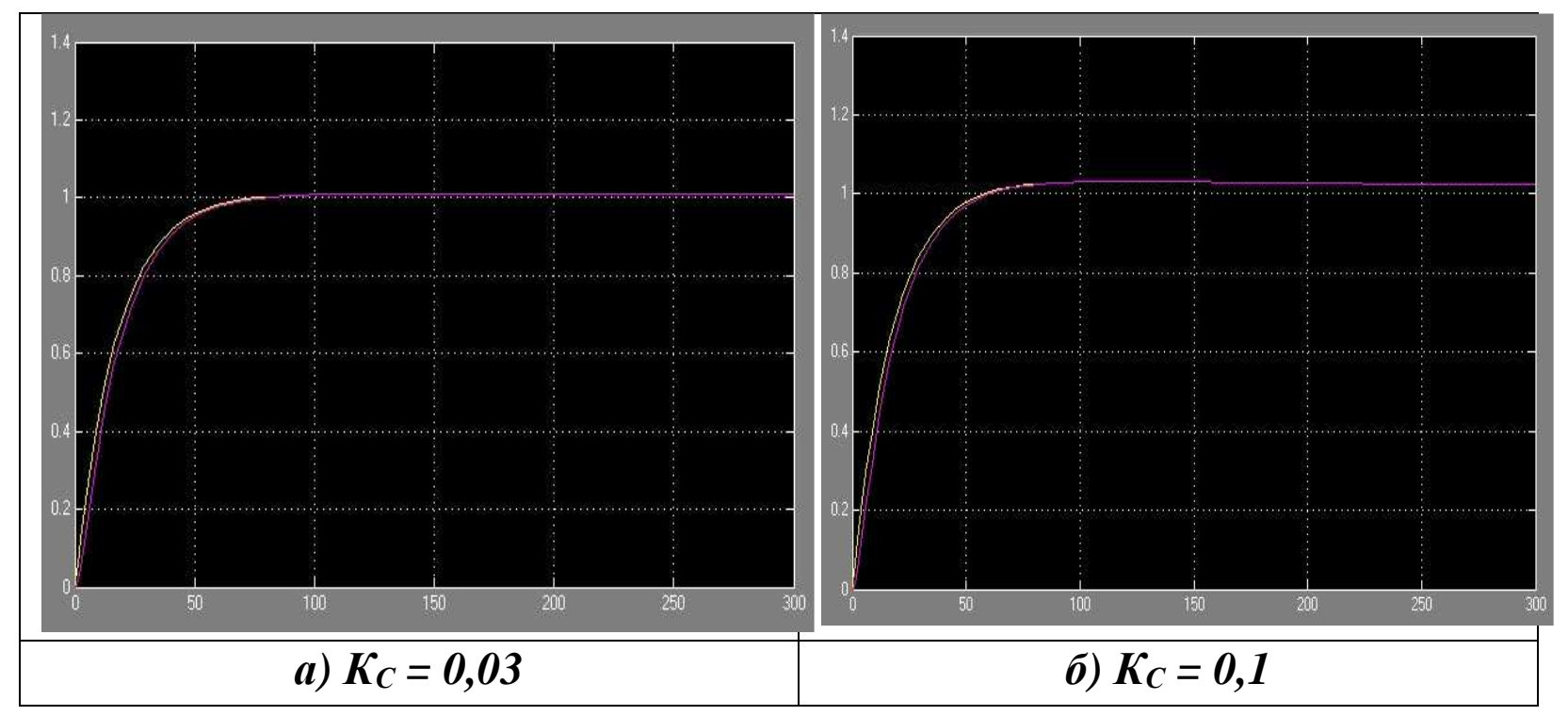

Рисунок 8 - Переходные процессы в системе управления термическим оборудованием с П-законом

\section{Таблица 2 - Показатели качества П-регулятора}

\begin{tabular}{|c|c|c|}
\hline & $\boldsymbol{K}_{\boldsymbol{C}}=\mathbf{0 , 0 3}$ & $\boldsymbol{K}_{\boldsymbol{C}}=\mathbf{0 , 1}$ \\
\hline$t_{p}, c$ & 74 & 57 \\
\hline$\sigma, \%$ & 0 & 1,5 \\
\hline$\varepsilon_{y c m}$ & 0 & 0 \\
\hline
\end{tabular}

\section{4. Заключение}

Проведен анализ устойчивости и показателей качества САУ термоэлектрическим объектом в линейном приближении. Показано,что для управления термоэлектрическим объектом идентификации могут быть рекомендованы классические законы регулирования: П, ПИ. В результате использования ПИ-регулятора, переходной процесс происходит по сривнению с П - регулятором с несколько большей величиной перерегулирования, но уменьшается время регулирования.

\section{Список информационных источников}

[1] Пилипенко В.А. Быстрые термообработки в технологии СБИС. Мн.: Изд. центр БГУ. - 2004. - С. 240.

[2] Ни Зо. Использование нечетких регуляторов в системах управления технологическими процессами при производстве полупроводниковых микросхем // Автоматизация и управление в технических системах. - 2012. - № 2. -С. 22-28. URL: auts.esrae.ru/2-18 (дата обращения: 22.12.2013).

[3] Ни Зо, Николаев А.Б. моделирование полупроводниковых микросхем с использованием термоэлектрического способа // Автоматизация и управление в 
технических системах. - 2012. - № 2. - С. 28-38. URL: auts.esrae.ru/2-19 (дата обращения: 22.12.2013).

[4] Николаев А.Б., Ни Зо. Исследование системы автоматического управления термоэлектрическим объектом // Автоматизация и управление в технических системах. - 2013. - № 4.1. - C. 113-120. DOI: 10.12731/2306-1561-2013-4-18.

[5] Николаев А.Б., Ни Зо. Моделирование процессов распространения тепла в термоэлектрических материалах // Автоматизация и управление в технических системах. - 2014. - № 1.1. C. 3-13. DOI: 10.12731/2306-1561-2014-1-1.

[6] Теория автоматического управления. / Под редакцией А.А. Воронова: в 2-х ч. М.: Высшая школа, 1986. Ч.1: Теория линейных систем автоматического управления. - 367 с.

[7] Остроух А.В. Основы построения систем искусственного интеллекта для промышленных и строительных предприятий: монография / А.В. Остроух. - М.: OОО «Техполиграфцентр», 2008. - 280 с. - ISBN 978-5-94385-033-2.

[8] Остроух А.В. Информационные технологии в научной и производственной деятельности / [ред. А.В. Остроух] - М: ООО "Техполиграфцентр", 2011. - 240 с. ISBN 978-5-94385-056-1.

[9] Остроух А.В. Ввод и обработка цифровой информации: учебник для нач. проф. образования / А.В. Остроух. - М.: Издательский центр «Академия», 2012. - 288 с. - ISBN 978-5-7695-9457-1.

[10] Остроух А.В. Исследование начального периода моделирования на точность среднеинтегральной оценки имитационных моделей / А.В. Остроух, А.А. Солнцев, Н.В. Солдатов, К.А. Новицкий, П.С. Якунин // Вестник МАДИ. - 2010. Вып. 2(21). - С. 61-65.

[11] Остроух А.В. Системы искусственного интеллекта в промышленности, робототехнике и транспортном комплексе: монография / A.B. Остроух Красноярск: Научно-инновационный центр, 2013. - 326 с. - ISBN 978-5-90631410-9.

[12] Nickolayev A.B., Ostroukh A.V., Zamytskikh P.V., Gubanov A.I. Automated system of oil quantity and quality indexes estimation // EUROPEAN JOURNAL OF NATURAL HISTORY. - 2011. - № 3 - C. 96-98.

[13] Остроух А.В., Тянь Юань. Современные методы и подходы к построению систем управления производственно-технологической деятельностью промышленных предприятий // Автоматизация и управление в технических системах. - 2013. - № 1(3). - C. 29-31.

[14] Остроух А.В. Интеграция компонентов системы мониторинга / А.В. Остроух, Юань Тянь // Молодой ученый. - Чита: ООО «Издательство Молодой ученый», 2013. - №10. - С. 182-185.

[15] Остроух А.В., Николаев А.Б., Сальный А.Г., Кухаренко В.Н. Общие принципы построения SCADA-систем // Автоматизация и управление в технических системах. - 2013. - № 2(4). - С. 8-12. 